The differences observed in neuropsychological test results might represent a trait characteristic of a particular group of patients who have frequent hypoglycaemia without having received intensified insulin treatment. The authors were also well aware of this possibility.

Diabetic patients with near normoglycaemia differ from people without diabetes with regard to substrate utilisation in the brain and regional cerebral blood flow during normoglycaemia..$^{33}$ These diabetic patients did not, however, differ from their non-diabetic counterparts in neuropsychological function..$^{33}$ The differences observed in blood flow and substrate utilisation are therefore probably not related to any anatomical defects of clinical significance.

Intensified conventional insulin treatment, which retarded the development of microvascular diabetic complications, led to an increased frequency of serious hypoglycaemic episodes, during which patients needed help from someone else and which more often resulted in hypoglycaemic coma. Although these episodes were upsetting for patients and potentially dangerous - for example, if they occurred when driving a car - they did not cause permanent cognitive deficit.

Grants were received from NOVO-Nordisk (Swedish division), Boehringer Mannheim Scandinavia, and the Swedish Medical Research Council (06615).

1 Reichard P, Berglund B, Britz A, Cars I, Nilsson BY, Rosenqvist U. Intensified conventional insulin treatment retards the microvascular complications in insulin dependent diabetes mellitus (IDDM): the Stockholm diabetes

2 Reichard P, Berglund B, Britz A, Levander S, Rosenqvist U. Hypoglycemic episodes during intensified insulin treatment: increased frequency but no effect on cognitive function. I Intern Med 1991;229:9-16.

3 Bale RN. Brain damage in diabetes mellitus. Br f Psychiatry 1973;122:337-41.

4 Ryan C, Vega A, Drash A. Cognitive deficits in adolescents who developed diabetes early in life. Pediatrics 1985;75:921-7.

5 Wredling R, Levander S, Adamson U, Lins PE. Permanent neuropsychological impairment after recurrent episodes of severe hypoglycaemia in man. Diabetologia 1990;33:152-7.

6 Cryer PE, Binder C, Bolli GB, Cherrington AD, Gale EAM, Gerich JE, et al. Conference summary. Hypoglycemia in IDDM. Diabetes 1989;38:1 193-9.

7 Reichard P, Britz A, Cars I, Nilsson BY, Sobocinsky-Olsson B, Rosenqvist U. The Stockholm diabetes intervention study (SDIS): 18 months' results. Acta Med Scand 1988;224:115-22.

8 Reichard P, Rosenqvist U. Nephropathy is delayed by intensified insulin treatment in patients with insulin-dependent diabetes mellitus and retinopathy. I Intern Med 1989;226:81-7.

9 Gerich JE. Glucose counterregulation and its impact on diabetes mellitus. Diabetes 1988;37:1608-17.

10 Ludin H-P. Electromyography in practice. Stuttgart: Thieme, 1980.

11 Goldberg JM, Lindblom U. Standardised method of determining vibratory perception thresholds for diagnosis and screening in neurological investigation. F Neurol Neurosurg Psychiatry 1979;42:793-803.

12 Fruhstorfer H, Lindblom U, Schmidt WG. Method for quantitative estim tion of thermal thresholds in patients. 7 Neurol Neurosurg Psychiaty 1976;39:1071-5.

13 Levander S. Evaluation of cognitive impairment using a computerized neuropsychological test battery. Nordisk Psykiatrisk Tidskrift 1987;41:417-22.

14 Levander S, Elithorn A. An automated psychological test system. APT manual version 1.0. Trondheim: Department of Psychiatry and Behavioural Medicine, University of Trondheim, 1987.

15 Levander S, Hägermark $O$, Stâhle M. Peripheral antihistamine and centra sedative effects of three H1-receptor antagonists. Eur $\mathcal{F}$ Clin Pharmaci $1985 ; 28: 523-9$

16 Levander SE, Bartfai A, Schalling D. Regional cortical dysfunction in schizophrenic patients studied by computerized neuropsychological methods. Percept Mot Skills 1985;61:479-95.

17 Cohen L. Perceptions of reversible figures after brain injury. Archives of Neurology and Psychiatry 1959;81:765-75.

18 Lezak MD. Neuropsychological assessment. 2nd ed. New York: Oxford University Press, 1983:556.

19 Lezak MD. Neuropsychological assessment. 2nd ed. New York: Oxford University Press, 1983:25-30.

20 Elithorn A, Mornington S, Stavrou A. Automated psychological testing: some principles and practice. International fournal of Man-Machine Studies principles and

21 Gardner MJ, Altman DG. Confidence intervals rather than $P$ values: estimation rather than hypothesis testing. $B M 7$ 1986;292:746-50

22 Thorsteinson B, Pramming S, Lauritzen T, Binder C. Frequency of daytime biochemical hypoglycaemia in insulin-treated diabetic patients: relation to daily median blood glucose concentrations. Diabetic Med 1986;3:147-51.

23 Lager I, Attvall S, Blohme G, Smith U. Altered recognition of hypoglycaemic symptoms in type 1 diabetes during intensified control with continuous subcutaneous insulin infusion. Diabetic Med 1986;3:322-5.

24 Amiel SA, Sherwin RS, Simonson DC, Tamborlane WV. Effect of intensive insulin therapy on glycemic thresholds for counterregulatory hormone release. Diabetes 1988;37:901-7.

25 Auer RN, Olsson Y, Siesjö B. Hypoglycemic brain injury in the rat. Correlation of density of brain damage with the EEG isoelectric time: quantitative study. Diabetes 1984;33:1090-8.

26 Agardh C-D, Kalimo H, Olsson Y, Siesjö BK. Hypoglycemic brain injury. I. Metabolic and light microscopic findings in rat cerebral cortex during profound insulin-induced hypoglycemia and in the recovery period following glucose administration. Acta Neuropathol (Berl) 1980;50:31-41.

27 Kalimo H, Agardh C-D, Olsson Y, Siesjö BK. Hypoglycemic brain injury. II. Electron microscopic findings in rat cerebral cortical neurons during profound insulin-induced hypoglycemia and in the recovery period followprofound insulin-induced hypoglycemia and in the recovery period
ing glucose administration. Acta Neuropathol (Berl) 1980;50:43-52.

28 Holmes CS, Hayford JT, Gonzales JL, Weydert JA. A survey of cognitive functioning at different glucose levels in diabetic persons. Diabetes Care 1983;6:180-5

29 Holmes CS, Koepke KM, Thompson RG. Simple versus complex performance impairments at three blood glucose levels. Psychoneuroendocrinolog 1986;11:353-7.

30 Herold KC, Polonsky KS, Cohen RM, Levy J, Douglas F. Variable deterioration in cortical function during insulin-induced hypoglycemia. Diabetes 1985;34:677-85.

31 Reichard P, Britz A, Carlsson P, Cars I, Lindblad L, Nilsson BY, et al. Metabolic control and complications over 3 years in patients with insulin dependent diabetes (IDDM): the Stockholm diabetes intervention study (SDIS). F Intern Med 1990;228:511-7.

32 Holmes CS, Tsalikian E, Yamada T. Blood glucose control and visual and auditory attention in men with insulin-dependent diabetes. Diabetic Med $1988 ; 5: 634-9$

33 Grill V, Gutniak M, Biörkman O, Lindqvist M, Stone-Elander S, Seitz RJ, et al. Cerebral blood flow and substrate utilization in insulin-treated diabetic subjects. Am F Physiol 1990;258:E813-20.

(Accepted 25 September 1991)
Department of Psychology, University College

London, London WC1E 6BT

Maeve Ennis, BA, Medica

Protection Society research fellow

BMF 1991;303:1442-3

\section{Training and supervision of obstetric senior house officers}

\section{Maeve Ennis}

Recent reports suggest that there are inadequacies in the training of junior hospital doctors. ${ }^{1-3}$ We carried out a study at four teaching hospitals and three district general hospitals to examine training of junior hospital doctors in obstetrics.

\section{Subjects, methods, and results}

Doctors were questioned on training, communication, and supervision and on the amount of responsibility they were given, and whether they had been involved in incidents and emergencies, and what the outcome was. The doctors were interviewed twice with the same format, once in their first month in an obstetric unit and again five months later. All senior house officers in each unit were interviewed.
At the first interview there were 39 senior house officers in the study, and at the second interview 26

The study focused on two aspects: use of forceps and cardiotocograms; these were aspects of most concern according to an analysis of cases that had come to litigation. ${ }^{1}$ Training in the use of forceps was defined as being shown by a registrar how to use forceps and using them at least once with a registrar in attendance. Training in cardiotocography was defined as formal training such as a tutorial or, at least, a registrar reviewing some cardiotographs and explaining what is or is not an abnormal or equivocal trace.

At the end of six months in an obstetrics unit six $(23 \%)$ senior house officers had had no training in the use of forceps, although three of them said that they had used them. Of the 20 senior house officers who had been trained, seven $(35 \%)$ thought that their training had been less than adequate. Half (13) of the senior house officers had had no formal training in interpreting or recognising abnormal or equivocal cardiotocograms, most of whom said that they had learnt what they knew by trial and error, their mistakes being identified and pointed out to them later by midwives and, sometimes, 
registrars. Of those who had had some training, three $(23 \%)$ thought that it had been less than adequate.

Most supervision was done by registrars; some senior house officers, both in the early weeks of the study $(10,26 \%)$ and at the end of six months $(3,12 \%)$, however reported having had little or no supervision. Asked "How often do you find yourself the responsible doctor in a ward or clinic without back up or support?" $31(79 \%)$ said seldom or never at the first interview and $18(69 \%)$ said seldom or never at the second. Eleven (28\%), however, reported at the first interview that they had had to act alone in an emergency and eight $(31 \%)$ at second. Twenty three $(58 \%)$ thought that they were inadequately prepared for the work they were expected to do in an obstetrics unit at both the first interview and the subsequent interview.

\section{Comment}

Although the sample size in this study is small, it is representative in that data were collected in both teaching hospitals and general district hospitals in seven different areas of the country and only in large hospitals.

These results suggest that these are aspects of training that need re-evaluation. Senior house officer posts are training posts, and doctors in them should have time to learn and receive feedback on their performance. A recent report suggested that senior house officers in all specialties should participate in ordered and structured teaching, ${ }^{3}$ but training in these posts generally remains poor. ${ }^{2}$ Most obstetric senior house officers in this study, even in academic departments, reported receiving only one or two hours' teaching or lectures a week and some in smaller district general hospitals received even less.

Experience is not necessarily a substitute for training; it seems only to increase confidence but not skill. ${ }^{45}$ Recognition at all levels that the senior house officer grade is a training grade is called for, with more comprehensive and intensive training that concentrates on those aspects of practice in which problems commonly arise. This would be of particular long term help to senior house officers continuing in a specialty and would benefit all senior house officers and improve patient care.

I thank Dr C Orr, Medical Protection Society, and Professor J O Drife for their comments on the manuscript, and the study participants. The study is part of a Medical Protection Society project directed by Professor R J Audley on avoidable mishaps in medicine.

1 Ennis $M$, Vincent $C$. Obstetric accidents: a review of 64 cases. $B M \mathcal{J}$ 1990;300:1365-7.

2 Grant J, Marsden P, King R. Senior house officers and their training. I. Personal characteristics and professional circumstances. II. Perceptions of service and training. BMF 1989;299:1263-8.

3 General Medical Council Education Committee. Recommendations on the training of specialists. London: GMC, 1987

4 Wynne G, Marteau TM, Johnson M, Whiteley CA, Evans TR. Inability of trained nurses to perform basic life support. BMF 1987;294:1198-9.

Marteau TM, Wynne G, Koyce W, Evans TR. Resuscitation: experience wia TM, Wyne G, Koyce W, Evans TR, Resuscitation. experience

(Accepted 20 August 1991)

\section{Roles of midwives and general practitioners in hospital intrapartum care, England and Wales, 1988}

\author{
Lindsay F P Smith, David Jewell
}

\section{General Practice Unit, Department of \\ Epidemiology and Public \\ Health Medicine, \\ University of Bristol, \\ Bristol BS8 2PR \\ Lindsay F P Smith, MRCGP, honorary research fellow \\ David Jewell, MRCGP, \\ consultant senior lecturer}

Correspondence to: Dr Smith.

BMF 1991;303:1443-4
The roles of both midwives ${ }^{1}$ and general practitioners in intrapartum care have changed over the past 30 years as delivery in hospital has increased. ${ }^{2}$ Such changes have generated debate about the responsibilities of the two professions. It has been proposed that an extended role for midwives, working only with consultant staff, would obviate the need for general practitioners in intrapartum care. ${ }^{3}$

As part of a larger survey ${ }^{4}$ we examined the working relationships between midwives and general practitioners in maternity units in England and Wales.

\section{Subjects, methods, and results}

The full methods have been reported elsewhere.$^{4} \mathrm{All}$ maternity units in England and Wales were asked about their activities in 1988. Each unit was asked to define itself as either a consultant unit (no general practitioner booked cases) or a general practitioner unit classified as isolated (geographically: separate), alongside (functionally separate), or integrated (using same wards as consultant cases).

We analysed the returned questionnaires using the Kruskal-Wallis test or $\chi^{2}$ test. Significance was defined as $p<0.01$ to allow for the large number of comparisons.

We received replies from 277 (93\%) of 297 maternity units identified. Of 611644 deliveries reported to the survey, 36043 (5.9\%) were booked for hospital general practitioner care and $8753(1 \cdot 4 \%)$ were domino deliveries (overseen by community midwives in hospital). The availability of domino deliveries varied, being more often available in integrated general practitioner units $(84 / 133(63 \%) v 27 / 65(42 \%)$ in isolated units, $11 / 29(38 \%)$ in alongside units, and $27 / 49(53 \%)$ in consultant units; $\left.\chi^{2}=11 \cdot 6, \mathrm{df}=3, \mathrm{p}<0 \cdot 01\right)$. Of 149 units providing this service, 123 were able to give numbers of deliveries. The median number of domino deliveries (interquartile range; number of units with such deliveries) was seven (two to $21 ; 20$ ) for isolated, 12 (five to 59 ; nine) for alongside, and 54 ( 26 to $129 ; 70$ ) for integrated general practitioner units and 37 (20 to $70 ; 24)$ for consultant units. Isolated units had significantly fewer domino deliveries than integrated or consultant units and alongside units significantly fewer than integrated units $(\mathrm{H}=26 \cdot 3, \mathrm{df}=3, \mathrm{p}<0 \cdot 001)$.

The table shows that midwives and general practitioners were more involved in the audit of isolated units $(\mathrm{p}<0.001)$ and less in perinatal meetings in consultant units $(p<0.01)$. In integrated general practitioner units both midwives and general practitioners were likely to be excluded from deciding booking policy $(p<0.01)$ and which general practitioners should be allowed to practise within the unit $(p<0.001)$.

Midwives in isolated units were less likely to suture and to read cardiotocographs than those in other units (table). Isolated units were less likely to train student midwives.

\section{Comment}

Most midwives have extended their skills, except in isolated general practitioner units. The extended role may reflect a shift away from providing personal care to low risk women towards the more technical approach often espoused by obstetricians.

General practitioners have traditionally provided personal continuity of care by attending their patients during labour and at delivery. Integrated general practitioner units with few general practitioner bookings ${ }^{4}$ 